\title{
Enfermería y su valor social
}

\section{Nursing in times of COVID-19}

\author{
Rocío B. Mayorga-Ponce ${ }^{a}$ y Brenda A. González Monter ${ }^{b}$
}

\begin{abstract}
:
Nursing has always been a profession that acts autonomously and is defined as a meaningful, therapeutic and interpersonal process. Its main objective being to place the patient in the best possible health state, for this, the nursing staff must act for the disabled person, help them to act or provide them with physical and psychological support, as well as education to learn to act for themselves. In this article I focus on making known in a well-founded way from several previously reviewed bibliographies, the importance and social value that nursing has had over time and what impact it has in the current situation of COVID-19.
\end{abstract}

Keywords:

Nursing, profession, COVID-19

Resumen:

Enfermería siempre ha sido una profesión que actúa de manera autónoma y se define como un proceso significativo, terapeútico e interpersonal. Siendo su principal objetivo situar al paciente en el mejor estado de salud posible, para ello, el personal enfermero debe actuar por la persona incapacitada, ayudarla a actuar o brindarle el apoyo físico y psicológico, así como la educación para aprender a actuar por si misma. El presente manuscrito se enfoca a dar a conocer de manera fundamentada desde varias bibliografías previamente revisadas, la importancia y el valor social que ha tenido enfermería a través del tiempo y qué impacto tiene ante la actual situasión de COVID-19.

Palabras Clave:

Enfermería, profesión, COVID-19

\section{Introducción}

La Enfermería abarca los cuidados -autónomos y en colaboración- que se prestan a las personas de todas las edades, familias, grupos y comunidades, enfermos 0 sanos, en todos los contextos, e incluye la promoción de la salud, la prevención de la enfermedad y los cuidados de los enfermos, discapacitados y personas en estado terminal. Las Funciones esenciales de la Enfermería son la defensa, el fomento de un entorno seguro, la investigación, la formación, la participación en la política de salud y en la gestión de los pacientes y los sistemas de salud, segun el Consejo Internacional de Enfermería ${ }^{1}$.
El valor social de la Enfermería refleja sobre los alcances teóricos de la formación de la profesión con respecto a la misión social del cuidado profesional, y en virtud de las amenazas que vivencian comunidades vulnerables como también sus efectos en la salud de los propios profesionales. Es necesario comprender el concepto y todo lo que abarca su aplicación, a lo largo del tiempo Enfermería ha demostrado ser un pilar fundamental en el Sistema Nacional de Salud, los profesionales son capaces de potenciar la resiliencia social, participando en el enfrentamiento de los desastres naturales y los profundos conflictos sociales vividos. De este modo, trabajar en resiliencia comunitaria es participar activamente en la

a Autor de Correspondencia, Universidad Autónoma del Estado de Hidalgo, https://orcid.org/0000-0003-3544-7171, Email: rmponce@uaeh.edu.mx

b Universidad Autónoma del Estado de Hidalgo, https://orcid.org/0000-0002-3903-2590, Email: go262777@uaeh.edu.mx 
superación de la vulnerabilidad social ${ }^{2}$. La historia ha dado a la Enfermería la incomparable misión social del cuidado de la vida, así cómo de la calidad de la misma. De esa manera, el futuro de la salud depende principalmente del papel social para conseguir una atención adecuada en. Como práctica social, la Enfermería es una profesión dinámica, sujeta a cambios constantes, siendo necesario creer que éstos son posibles y que deben ser implantados. Estas acciones transformadoras son frutos de reflexiones sobre los nuevos problemas, siempre guiándose por el principio ético de mantener o restaurar la dignidad en todos los ámbitos de la vida, y aún después de la muerte es impresindible que el personal enfermero realice las adecuadas intervenciones desde un punto de vista tanatológico hasta tener que realizar los cuidados postmortem. En pocas palabras, Enfermería es una pieza clave que acompaña a la vida humana desde el momento en el que ésta nace y hasta que ésta se acaba ${ }^{3}$.

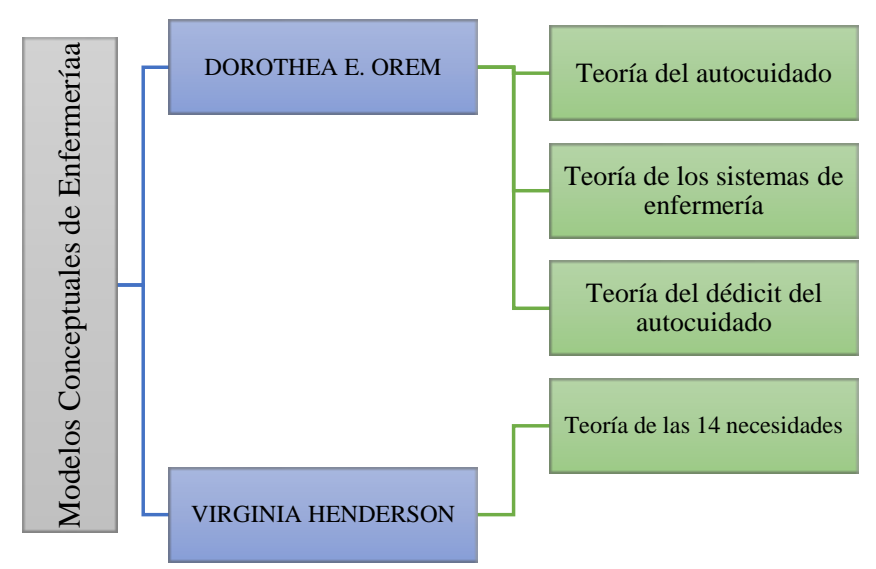

Figura 1 Modelos conceptuales de Enfermería

\section{Enfermería en primera línea ante COVID-19}

Para casi todos los profesionales de la salud, esto es completamente nuevo. Era esperado que el número de personas infectadas con la COVID-19 iba a aumentar, pero no que fuera a ocurrir tan aceleradamente. $Y$ vamos a continuar viendo un incremento impresionante en los números, porque muchos pacientes regresan unos días después al empeorar sus síntomas. El virus trae conigo complicaciones sonre todo en pacientes que padecen alguna enfermedad crónico degenerativa.

Son unas circunstancias de mucho estrés para todos los profesionales de la salud e incluso para los pacientes. Todo el personal de salud hace lo mejor para prestarle a los pacientes los mejores cuidados posibles, pero a la vez ellos deben proteger su integridad, así como sus familiares. Sin duda alguna El sistema de Salud ha mostrado resiliencia ante la actual situación sanitaria, pero hay que brindar un reconocimiento alargado a todos los profesionales de Enfermería que están actuando como pieza clave y fundamental, siendo ellos el pilar más grande que actua en primela fila ante al emergencia sanitaria. Cada profesional de la enfermería es un ser humano que a pesar de los retos que presenta la pandemia, siempre trabajará con valores universales y éticos en atención de los pacientes ${ }^{4}$.

El 80 por ciento de la carga de atención al paciente con COVID-19 recaen sobre el personal de enfermería, teniendo día con día grandes retos, que con ayuda de las habilidades y los conocimientos de los profesionistas son capaces de mantener los valores universales y los valores éticos de la profesión, que han distinguido Enfermería como una disciplina humanitaria respetando y cuidando siempre la vida y los derechos humanos de cada uno de los pacientes ${ }^{5}$.

\section{Referencias}

[1] Paula Alina Juarez Rodriguez. La importancia del Cuidado de Enfermería. Rev Enferm Inst Mex Seguro Soc. 2009; Vol. 17 no. 2 : $109-111$

[2] León Román CA. Enfermería como profesión y ciencia. En: Bello Fernández NL, editor. Fundamentos de Enfermería. Ira pt. La Habana: Editorial Ciencias Médicas; 2006. p. 1-99.

[3] Carlos A. León Román. Nuevas teorías en Enfermería y precedentes de la historia. Revista Cubana de Enfermería. 2017; Vol. 33: 4 págs.

[4] Luz Angélica Muñoz. El valor Social de Enfermería. Archives of Health Sciences. 2017; Vol. 24 no. 2: DOI: https://doi.org/10.17696/23183691.24.2.2017.877

[5] Juan J. García Iglesias. Impacto del SARS-CoV-2 en la salud mental de los profesionales sanitarios. Rev Esp Salúd Pública 2020; Vol. 94 no. 23:20 págs. 